\title{
Artelogie
}

artelogie Recherche sur les arts, le patrimoine et la littérature de l'Amérique latine

14 | 2019

Sensibilités : Arts, littératures et patrimoine en Amérique latine

\section{La infancia rural en César Vallejo: renovación cultural y crítica social}

Alejandra Josiowicz

\section{OpenEdition}

12 Journals

Edición electrónica

URL: http://journals.openedition.org/artelogie/4020

DOI: $10.4000 /$ artelogie.4020

ISSN: 2115-6395

Editor

Association ESCAL

Referencia electrónica

Alejandra Josiowicz, «La infancia rural en César Vallejo: renovación cultural y crítica social », Artelogie [En línea], 14 | 2019, Publicado el 07 enero 2019, consultado el 17 septiembre 2019. URL : http:// journals.openedition.org/artelogie/4020 ; DOI : 10.4000/artelogie.4020

Este documento fue generado automáticamente el 17 septiembre 2019

Association ESCAL 


\title{
La infancia rural en César Vallejo: renovación cultural y crítica social
}

\author{
Alejandra Josiowicz
}

1 Este trabajo analiza la "escena" de infancia en una selección de textos poéticos y narrativos del escritor peruano César Vallejo (1892-1938). Se analizan textos provenientes de distintos géneros discursivos y literarios - literatura infantil, crónica, poesía y prosa poética -, como modalidades diferentes y complementarias por las cuales Vallejo construye una "escena" de infancia': en esas diferentes instancias discursivas, la infancia emerge no únicamente como público lector o como tema representado, sino como motor fundamental de la escritura, modo de percepción, constelación de afectos y modos de interpretación de la experiencia. En tanto “escena” (RANCIÈRE, 2013: 11), la infancia apunta más allá de la pura percepción individual de un autor, Vallejo, hacia la comprensión de un horizonte colectivo, sensible e intelectual, de representaciones y modos de entender la niñez en América Latina y en Perú en la época.

2 Este trabajo se propone estudiar prácticas culturales de lo sensible en relación con la infancia y específicamente de la niñez como signo de la alteridad, utilizando como marco el estudio de las sensibilidades como objeto de la historia cultural, matriz de sensaciones y sentimientos y modo de interrogar la subjetividad y la socialización (PESAVENTO, 2007). El mundo afectivo ligado a la infancia está encarnado en la corporalidad y en los sentidos, tanto en lo táctil, visual y oral como en lo gustativo (SEDGWICK, 2003). Se aborda el modo por el cual la infancia campesina e indígena fue pensada y sentida en la época, estableciendo relaciones con el horizonte de debates de las vanguardias europeas y latinoamericanas sobre el tema, así como de una serie de intelectuales, reformadores sociales, pedagogos, médicos y juristas latinoamericanos preocupados con su estatus social. ¿En qué sentido la infancia rural, campesina, aparece en el imaginario y en la percepción de un escritor como Vallejo? ¿A través de qué tipos de lenguaje, qué tipo de imágenes y modos de la percepción la infancia emerge en el horizonte colectivo, en los sentimientos y valoraciones de los intelectuales de la época? La hipótesis que guia el presente trabajo es que, dada su invisibilidad para la mayor parte de los discursos sociales, la sensibilidad del niño campesino, criado, indígena o pobre aparece en los textos 
de Vallejo a través de una ruptura de la forma de representación y de las convenciones lingüístico-discursivas. Es a través de un quiebre formal que Vallejo consigue explorar la sensibilidad del niño indígena, criado, cuya experiencia es invisible, indecible y caótica. Para eso, crea una estética fantasmal, sombría, que explora los sentidos táctiles, visuales y gustativos de la experiencia infantil en lugar de dar cuenta de la infancia marginada como tópico o contenido referencial: de ese modo, el niño marginado es mucho más un núcleo de afectos y percepciones sobre un mundo caído que un sujeto a ser visibilizado por el texto o el autor.

3 Con ese fin, se establecen relaciones, por un lado, con el modo en que las vanguardias europeas y latinoamericanas concibieron a la infancia como instancia de transgresión y experimentación con los lenguajes estéticos $\mathrm{y}$, por otro, con los debates de una serie de intelectuales, reformadores sociales, médicos y pedagogos sobre la infancia marginada, alrededor de cuestiones sociales y modelos pedagógicos en América Latina. La primera parte de este trabajo aborda ese doble horizonte de debates estéticos y políticos sobre el tema. En la segunda parte, se discute el modo en que el poemario Trilce (1922) apunta a la infancia como un modo de transgresión de las jerarquías gramaticales y de emergencia de un lenguaje renovador, desarticulado y balbuceante, de lo disonante y lo inconsciente, que apunta hacia la oralidad y la materialidad lingüística. En la tercera parte, más extensa, se estudia el cuento infantil Paco Yunque (1931) y una selección de poemas escritos entre 1930 y 1940, incluidos en España, aparta de mí este cáliz (1939) y Poemas Humanos, publicados en forma póstuma. Allí, se analiza la representación del niño indígena campesino y su marginación por parte de las instituciones del Estado. El niño emerge como un modo de denuncia social, como síntoma de las dificultades y desafíos en el proceso de democratización en América Latina. De ese modo, se argumenta que en los textos de Vallejo la infancia combina un posicionamiento político alrededor de la infancia excluida o marginada y una serie de búsquedas formales de experimentación estética ligadas a la sensibilidad infantil. Lejos de un mero referente, el niño constituye un modo de conciliar la experimentación formal con preocupaciones sociales y étnicas. A través de un lenguaje no referencial y de una serie de búsquedas estético-políticas y sociales, Vallejo explora la sensibilidad del niño criado, marginado, indígena y campesino.

\section{Un horizonte cultural y político de debates sobre la infancia}

4 Una de las características más salientes de las vanguardias latinoamericanas es la conjunción de una preocupación por la especificidad cultural, por lo oral, lo regional y lo folklórico, y una estética transgresora, de lo disonante y lo fragmentario (UNRUH, 1994). Las vanguardias latinoamericanas reconfiguran la jerarquía geopolítica que daba primacía a Europa en pos de una identidad híbrida, antropofágica, carnavalizada ( ROSENBERG, 2006 y 2008). La infancia fue objeto de debate en la cultura peruana de las primeras décadas del Siglo, entre aquellos críticos conservadores que atacaban el infantilismo de las vanguardias y los progresistas e indigenistas que lo aplaudían como signo de un nuevo comienzo superador de los modelos europeos (CLAYTON, 2011: 64-69). La exploración de la infancia permitió a varios movimientos de vanguardia latinoamericana - como es el caso de la vanguardia puertorriqueña y la brasileña superar la dicotomía entre arte puro, autónomo, y arte político (JOSIOWICZ, 2016 y 2018). Este trabajo examina textos líricos y narrativos destinados al público infantil y adulto 
escritos por César Vallejo como condensación de un doble tipo de indagación: en primer lugar, con el lenguaje infantil, en un estado previo a la formación de lo simbólico, en segundo lugar, con el niño como puesta en escena de una serie de preocupaciones sociopolíticas.

Los vanguardistas latinoamericanos cuestionan el retrato romántico del niño como objeto de nostalgia y sentimentalismo, ${ }^{2}$ subordinado a la imagen del adulto, modo de fijar la identidad individual y patriótica en el tiempo (MOLLOY, 1991: p. 96). Lectores ávidos de las vanguardias europeas - del surrealismo francés, el dadaísmo y el expresionismo alemán -, los vanguardistas latinoamericanos también siguieron muy de cerca el proyecto psicoanalítico de exploración del inconsciente. En las artes plásticas, las vanguardias europeas - el art brut, el infantilismo de Picasso, Kandinsky y otros - utilizaron el trazo pueril del niño como un modo de ruptura con la tradición (FRANCIOLLI, 2004). El surrealismo francés teoriza el lugar del niño como escenficación de un acceso directo al inconsciente: a través del automatismo psíquico o la asociación automática, el artista surrealisa, según Breton, podía acceder al estado de plenitud y unidad originaria y liberatoria en que viven tanto el niño como el primitivo (FOSTER, 1993: 4). Como parte de su retórica de originalidad, el artista de vanguardia se identifica con el niño que emerge recién nacido directamente del líquido amniótico, sin ancestros, desde un grado cero de la creación estética, sin modelo, sin referente más allá de sí mismo (KRAUSS, 1988: 157). Los surrealistas representaron la infancia a través de una serie de fantasías intrauterinas primarias, de intimidad corporal y unidad psíquica con el cuerpo de la madre (FOSTER, 1993). A diferencia de la visión de plenitud idílica, orgánica y vitalista de la infancia del surrealismo y el futurismo, los vanguardistas latinoamericanos la conciben como atravesada por el sueño, el delirio, la hiperconciencia y la alienación, así como por la muerte, la desesperanza, el miedo y la lucha (BOSI, 2002: 28). En ese sentido, resulta comparable con el modo en que aparece en los debates alrededor del expresionismo. Alrededor de 1938, año de la muerte de Vallejo, Ernst Bloch y Georg Lukács sostienen un debate en la revista Das Wort sobre la relación entre vanguardia, realismo y crítica social. Así, mientras Lukács denuncia al expresionismo por su estética "decadente", su uso no referencial y puramente expresivo de las palabras, uso "atávico" del folklore, demolición de lo real, mundo desintegrado, caos y montaje (todo lo cual resultaría en una mistificación de la realidad, parasitaria de la ideología burguesa) (LUKÁCS, 2002), Bloch lo defiende como un modo de conciliar el sustrato popular, folklórico - del arte "barbárico, de los niños, los presos, los enfermos mentales, los primitivos y los iletrados" - con la elaboración formal del arte moderno (BLOCH, 2002). Por su lado, Bertold Brecht interviene y recupera el legado del expresionismo como resolución del dilema entre arte experimental de vanguardia y arte popular, conectado con las masas y aliado del realismo (BRECHT, 2002). Los textos de César Vallejo alrededor de la infancia apuntan justamente en esa dirección, dado que conjugan un uso altamente experimental del lenguaje, alrededor de la oralidad infantil, con un interés por lo popular, que investiga la sensibilidad del niño marginalizado, campesino e indígena.

6 Por otro lado, en las primeras décadas del siglo XX emerge una serie de discursos positivistas, higienistas, sociológicos, pedagógicos y criminalistas sobre el niño, alarmados ante las bajas tasas de alfabetización, altas tasas de abandono, mortalidad infantil, ilegitimidad y niños viviendo en la calle en América Latina, que empiezan a ser consideradas potenciales amenazas para el progreso nacional, para los planes futuros de desarrollo económico y la reputación internacional de las naciones latinoamericanas. ( 
LAVRIN, 1994: 52; Guy, 2009: 244). En este período, varios países de América Latina generalizan sus políticas hacia la salud física y moral de los niños como futuros ciudadanos: en 1923 la Liga de las Naciones emite la Declaración de los Derechos del Niño en Génova y en 1927 se crea el Instituto Interamericano del Niño en Montevideo, con delegados de Argentina, Bolivia, Brasil, Ecuador y Perú (BIRN, 2006)-, los países latinoamericanos dictan sus primeros Códigos del Niño - Brasil en 1927, Uruguay en 1934, Argentina en 1932, Chile y México en 1934 - y organizan Congresos Internacionales e Interamericanos de protección a la Infancia en los cuales se pone un énfasis específico en las responsabilidades de los Estados en el cuidado de los niños (GUY, 1998: 272-291 y 2002: 158). El niño latinoamericano también se vuelve fuente de interés para un grupo de escritores e intelectuales que - ante la expansión de las movilizaciones obreras, movimientos socialistas y anarquistas, la fundación de partidos comunistas y los golpes militares de las décadas de 1920 y 1930 - experimentan una profundización de sus preocupaciones sociales y políticas, e intervienen en debates sobre la educación infantil y el éxito o fracaso de las políticas estatales. ${ }^{3}$ En el marco de las Convenciones de Maestros o en las Semanas Pedagógicas que tienen lugar en varios puntos de América Latina en esas décadas, intelectuales como el peruano José Carlos Mariátegui (1894-1930), con quien Vallejo mantuvo un productivo diálogo, pugna por una mayor democratización social de la educación infantil. Mariátegui escribe "El proceso de la instrucción pública" (incluido en sus Siete ensayos de interpretación de la realidad peruana) publicado por primera vez en 1928, así como también una serie de ensayos aparecidos en revistas entre 1923 y 1929, denunciando el estatuto servil del niño pobre, indígena y mestizo en Perú, como consecuencia de las desigualdades de clase y de raza (MARIÁTEGUI, 1970 y 2005). Mariátegui advirtió sobre las contradicciones de instaurar el proyecto "demoliberal" y "burgués" de educación gratuita, laica y obligatoria en Hispanoamérica (MARIÁTEGUI, 2005 y 1970). Señaló la herencia feudal, colonial y aristocrática de la cultura letrada, así como las desigualdades de raza y de clase que impedían la implementación de una moderna educación capitalista, democrática y tecnificada en Perú. Argumentó que el problema educativo peruano era económico y social, y fue crítico del puro nominalismo de la escuela igualitaria, a la que consideraba opresora y aplanadora de la diferencia individual. Advirtió sobre la sumisión de los maestros de primera enseñanza a un caciquismo feudal y denunció la servidumbre social del niño pobre, indígena o mestizo ( MARIÁTEGUI, 2005 y 1970). Es en ese horizonte transnacional de debates sobre la escuela liberal, provenientes tanto del campo pedagógico estatal como del anarquismo y el socialismo que deben entenderse los escritos de César Vallejo alrededor de la infancia.

7 Por otro lado, existía en la sociedad andina de la época un mundo de prácticas sociales informales, extralegales y frecuentemente ilegales alrededor de la infancia: los niños ilegítimos, indígenas, huérfanos, pobres o migrantes del ámbito andino eran destinados al trabajo doméstico informal, sometidos por la institución del criadazgo - relación doméstica y de dependencia privada - no considerados como sujetos de derechos y casi absolutamente invisibilizados (MILANICH, 2005: 35). Es esta invisibilidad de los niños andinos sometidos a diferentes prácticas de explotación sistemática, de modo silencioso, como sirvientes en casas privadas, mantenidos al margen de la ley (MILANICH 2005), que Vallejo se propone recuperar en sus textos. 


\title{
Trilce o los ecos de la memoria
}

8 César Vallejo publica Trilce, su segundo libro de poemas, en 1922 en Lima. En una carta que escribe el mismo año de la publicación del poemario, Vallejo utiliza la metáfora del niño para referirse al libro:

\begin{abstract}
Los vagidos y ansias vitales de la criatura en el trance de su alumbramiento han rebotado en la costra vegetal, en la piel de reseca yerba de la sensibilidad literaria de Lima... Sólo algunos escritores jóvenes aún desconocidos y muchos estudiantes universitarios se han estremecido con su mensaje. Por lo demás, el libro ha caído en el mayor vacío. Me siento colmado de ridículo, sumergido a fondo en ese carcajeo burlesco de la estupidez circundante, como un niño que se llevara torpemente la cuchara por las narices.... ¡Y cuántas veces me he sorprendido en espantoso ridículo, lacrado y boquiabierto, con no sé qué aire de niño que se llevara la cuchara por las narices! En este momento casi revivo todo el fragor que dio vida a Trilce y a Los Heraldos Negros! (VALLEJO, 2002: 46-47).
\end{abstract}

9 Vallejo se refiere a Trilce a través de la imagen del niño recién nacido, que irrumpe en la escena poética como progenie de una sensibilidad literaria nueva - signo de fluidez y de un tipo de carnadura literaria inéditas - y encuentra una atmósfera infértil: la indiferencia y el rechazo de la cultura limeña de la época. El poeta también aparece asociado a la imagen del niño que, como un bufón o un payaso, gesticula histéricamente y transgrede las convenciones sociales - las costumbres en la mesa -, revelando el ridículo general en su performance soez ("llevarse torpemente la cuchara por las narices"). El niño-poeta es un fantoche que ha perdido control y agencia sobre su cuerpo ("me he sorprendido en espantoso ridículo, lacrado y boquiabierto"). Es síntoma de la "lacra pública", reflejo del malestar del medio, la "estupidez circundante" que ventriloquiza avergonzado. Como se ve, Vallejo condensa en la imagen del niño el nacimiento de una nueva política cultural, cuyo núcleo es la transgresión de la gramática legítima y la práctica de la impureza linguística.

10 La crítica ha señalado el hecho de que en Trilce el sujeto de la enunciación asume la voz del niño "en el momento mismo de la primera incertidumbre" (FRANCO, 1988: 580). Sin embargo, no hay nada ingenuo en Trilce sino que se postula un yo infantil que revela la orfandad del hablante, un sujeto que nace sin amparo en el lenguaje, que cuestiona la autoridad de los nombres y pone en escena la crisis de los códigos. Otros estudios han apuntado que el texto excenifica una crítica, una denuncia y un juego con la lengua y el proceso mismo de nombrar, por el cual el sujeto que "aprende a hablar" lo hace a partir de la pérdida del habla institucionalizada, de la asunción del balbuceo, la desarticulación, la onomatopeya, y de la imposición de neologismos, barbarismos y desviaciones ortográficas (ORTEGA, 1988: 609). La pérdida de la lengua institucionalizada, oficial y legítima implica en Vallejo una suerte de retroceso por el cual el poeta investiga el lenguaje en el momento previo a la constitución del sujeto, previo a la entrada en la norma lingüística y social. Se trata de una exploración de lo que Julia Kristeva ha teorizado como la ecolalia, el lenguaje del niño hecho de ritmos y entonaciones anteriores a los primeros fonemas o frases, lengua ante-predicativa que transgrede la sintaxis y cuestiona la nominación (KRISTEVA, 1981: p. 259).

11 En Trilce (1922), el niño aparece asociado al mundo oral, auditivo, a los ecos de la memoria:

Las personas mayores 
¿a qué hora volverán?

Da las seis el ciego Santiago,

Y ya está muy oscuro.

Madre dijo que no demoraría.

Aguedita, Nativa, Miguel,

Cuidado con ir por ahí, por donde

acaban de pasar gangueando sus memorias

dobladoras penas

hacia el silencioso corral y por donde

las gallinas se están acostando todavía.

Mejor estemos aquí no más.

Madre dijo que no demoraría. (VALLEJO, 1988: 172)

12 El poema escenifica la voz del niño como un coro de ecos, que resuenan, preguntan, evocan y apostrofan. Es una voz infantil fantasmática, una voz sin sujeto, sin origen ni destinatario. Sobre el sujeto que enuncia esas preguntas y sobre aquel a que se dirigen, sólo sabemos que se trata de una comunidad infantil, dada por la primera persona del plural, que opera como espacio de resonancia: la voz de un niño inmerso en la oscuridad uterina, en la superficie porosa de la memoria. Esta voz designa, más que un sujeto, únicamente un punto de vista, que es el del niño, un "nosotros" infantil y "aquí" que, desde un lugar menor y una relación de obediencia, está a la espera de la vuelta de los adultos, "ellos". El poema designa un estado de vulnerabilidad y desprotección: "cuidado con ir por ahí, por donde". El niño aparece como desprotegido ante los peligros invisibles que lo acechan, a la espera de una protección que vendría de los otros o del afuera. La infancia es ese "ahí" por donde pasan las memorias, un lugar de peligro, un abismo donde el sujeto se halla radicalmente desprotegido, un espacio hecho de voces sin referente preciso.

13 Años antes, entre 1911 y 1917, César Vallejo había escrito y publicado poemas juveniles y didácticos en la revista Cultura infantil, editada por el Centro Escolar de Varones en donde trabajaba como maestro. Vallejo fue empleado como tutor del hijo de un propietario de minas en la provincia de Pasco, Perú, luego trabajó como maestro en el Centro Escolar de Varones y más tarde, como maestro de escuela primaria en el Colegio Nacional de San Juan (Franco, 1976: p. 20). Se trata de poemas didácticos para lectores escolares, de tipo científico o instructivo, en los que el yo poético toma la voz del pedagogo, transmisor de conocimiento. Vallejo los compuso al mismo tiempo que escribía su tesis sobre "El romanticismo en la poesía Castellana", lo que explica el romanticismo y el tono sentimental a través del cual aparece la infancia (FRANCO, 1976: 25). En el poema "Barco Perdido", por ejemplo, se lee:

$¡ O h$ verde azul del agua entre alcanfores,

donde jugué a las naves,

las naves de mi infancia que fletara

con mis mieles mejores!

¡Oh lindo barco gualda que te fueras

yo no sabré hasta dónde!

Ahora que me ahogo en mi conciencia,

¡qué bueno si volvieras...! (VALLEJO, 1988: 141)

Se trata de una elegía nostálgica, en que un yo poético adulto recuerda sus juegos de la infancia. La niñez es metáfora de un pasado idílico, sentimental, romántico, que contrasta con un presente asfixiante. Estos poemas juveniles contrastan con la poética posterior de Vallejo, que cuestiona la temporalidad biográfica lineal. Esto aparece ya en el poema "A mi hermano Miguel" (1918), que Vallejo dedicó a su hermano muerto: 
Hermano, hoy estoy en el poyo de la casa,

donde nos haces una falta sin fondo!

Me acuerdo que jugábamos esta hora, y que mamá

nos acariciaba: "Pero, hijos..." (...)

Oye, hermano, no tardes

en salir. Bueno? Puede inquietarse mamá. (VALLEJO, 1988: 172)

El poema se inicia con la voz del adulto, que apostrofa al hermano perdido y rememora la escena de infancia. El uso del verbo "me acuerdo" y las comillas para citar la voz de la madre establecen una distancia entre el sujeto poético que recuerda y el niño rememorado. En los dos versos finales, sin embargo, el yo poético se transporta a la perspectiva del niño, tomando la voz infantil. Así, el niño recordado y el adulto que rememora se fusionan y se vuelven indistinguibles uno del otro. De este modo, el poema quiebra la lógica evolutiva que une niño y adulto, pasado y presente, generando un yo poético niño que rompe con la temporalidad lineal de la biografía. Como se ve en el ya citado poema 3, Trilce va aún más allá: allí el verbo del recuerdo desaparece completamente, dejando al desnudo la oralidad colectiva, sin sujeto, del niño:

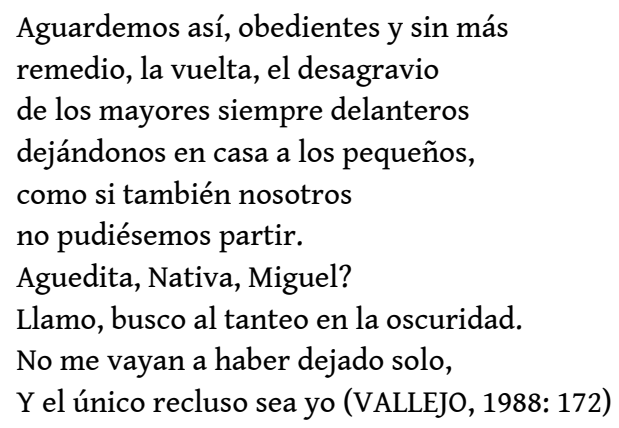

El final del poema establece una demarcación espacial, que sitúa a los niños en un territorio doméstico y en una situación de pasividad, mientras que los adultos se asientan en un espacio futuro que implica la partida, el abandono de la casa y de la infancia. En la última estrofa citada, mediante el uso del apóstrofe, el niño redescubre su territorio como un espacio oscuro, de soledad, de reclusión, como una cámara vacía.

Por otro lado, en el poema 52, el yo poético rompe con la identidad individual y construye una colectividad y un tipo de sensibilidad infantil:

Y nos levantaremos cuando se nos dé

la gana, aunque mamá toda claror

nos despierte con cantora

y linda cólera materna.

Nosotros reiremos a hurtadillas de esto,

Mordiendo el canto de las tibias colchas

De vicuña ¡y no me vayas a hacer cosas! (VALLEJO, 1988: 234)

18 En este poema, los niños desobedecen el mandato materno y enuncian su declaración de rebeldía. De este modo, el momento de despertar se transforma en espacio de placer sensorial y de sexualidad pícara. Se trata de una experiencia colectiva infantil, en que aparecen imágenes visuales, auditivas, musicales, táctiles y gustativas. La frase final registra el cuerpo juguetón del niño, pleno de deseo y sensualidad, que preanuncia los descubrimientos de Sigmund Freud y el psicoanálisis, con los que Vallejo solo entraría en contacto años después (FRANCO, 1976: 63).

Los niños aparecen inmersos en el paisaje rural:

Y llegas muriéndote de risa

Y en el almuerzo musical, 
Cancha reventada, harina con manteca

Con manteca,

Le tomas el pelo al peón decúbito

Que hoy otra vez olvida dar los buenos días,

Esos sus días, buenos con b de baldío,

Que insisten en salirle al pobre

Por la culata de la v

Dentilabial que vela en él. (VALLEJO, 1988: 234). iniciático y exploración de los sentidos. Se encuentra con el peón, se burla de su modo de hablar y lo incluye en su juego. La frase "le tomas el pelo al peón decúbito" señala una interpenetración verbal y corporal con la lengua y el cuerpo del criado que habla "mal": se trata de una lengua incivilizada, de materialidad consonántica, que infringe las normas del lenguaje. Esta unión o alianza entre la lengua del peón y la del niño, infractores del habla correcta y las buenas maneras, revela que ya en Trilce Vallejo había tomado distancia de lo que observaba como "pomposa teoría y abracadabrante método" del surrealismo (VALLEJO, 2002: 517-518). De hecho, Vallejo investigó la infancia no sólo en la dirección de una renovación formal del lenguaje sino como núcleo de una serie de preocupaciones sociales y políticas, indagando el estado de desprotección, desposesión y orfandad de los niños marginados en América Latina.

\section{Hacia una política de la infancia en César Vallejo}

21 A partir del período de su viaje a París en 1923 y hasta su muerte en 1938, Vallejo se interesó por el marxismo y reflexionó sobre el rol político social del artista. Se mostró crítico de lo que percibía como puro esteticismo de las vanguardias europeas, sobre todo del surrealismo, pero también cuestionó el sometimiento del artista y su obra a cualquier programa político. ${ }^{4}$ En esta etapa de su trayectoria, que incluye el tomo conocido como Poemas Humanos, publicado en 1939 en París, así como los poemas de España, aparta de mí este cáliz y el cuento Paco Yunque, Vallejo, sin abandonar sus experimentos vanguardistas previos, logró aprehender de modo más completo cuestiones de representación política (CLAYTON, 2011: 192-249). En esos escritos, Vallejo denunció la situación de la infancia marginada en Perú, del niño indígena, pobre o migrante del ámbito andino, casi completamente invisibilizado, e intervino en los debate sobre la educación de la época.

En la prosa poética "Tendríamos ya una edad misericordiosa" (incluida en Poemas Humanos), se narra una escena hogareña familiar, en que mientras la madre cocina y el padre y los hermanos esperan sentados a la mesa, se escucha un llamado a la puerta: “¡Tocan a la puerta!". Este llamado escenifica la interpelación del niño por el Estado, su iniciación en la letra y su socialización en la institución escolar. “Tendríamos ya una edad misericordiosa cuando mi padre ordenó nuestro ingreso a la escuela", dice el texto. La "edad misericordiosa" es el momento en que la iniciación religiosa - la primera comunión, rito de pasaje del catolicismo - coincide con el ingreso a la escuela. Escuela e Iglesia aparecen profundamente imbricadas en el texto de Vallejo, como dos "aparatos ideológicos de Estado", de acuerdo con Louis Althusser, quien señaló que la escuela, como aparato ideológico dominante, reemplazó las funciones de la iglesia, ambos intrínsecamente relacionados con la institución familiar. ${ }^{5}$

23 De este modo, el texto de Vallejo pone en escena la transformación de individuo en sujeto. El llamado a la puerta, la interpelación, proviene de una fuerza innombrada que, 
desde afuera, irrumpe en el hogar materno, afectivo y nutricio y quiebra el equilibrio entre los hermanos. "Nativa lloraba de una tal visita, de un tal patio y de la mano de mi madre. Entonces y cuando, dolor y paladar techaron nuestras frentes." (VALLEJO, 1988: 318) El quiebre del núcleo familiar está reforzado desde el interior, dado que el hermano se hace eco del llamado: "Sin esperar la venia maternal, fuera Miguel, el hijo, quien salió a ver quién venía así, oponiéndose a lo ancho de nosotros.” (VALLEJO, 1988: 318). La salida de Miguel indica el desprendimiento del cuerpo hogareño y revela que la interpelación, proveniente del orden escolar estatal, constituye a los individuos en sujetos a través de un acto de mutuo reconocimiento, por el cual el sujeto se sabe interpelado por la ideología. Como parte de la misma genealogía masculina, el padre también es interpelado por esa fuerza foránea, invisible, del orden escolar que toca a la puerta:

¡Qué diestra de subprefecto, la diestra del padre, revelando, el hombre, las falanges filiales del hijo! Podía así otorgarle la ventura que el hombre deseara más tarde.

-Y mañana, a la escuela- disertó magistralmente el padre, ante el público semanal de sus hijos.

Y tal, la ley, la causa de la ley. Y tal también la vida. (VALLEJO, 1988: 319)

El padre enuncia la ideología escolar que señala un cuerpo disciplinado, una jerarquía masculina y oficial y un destino futuro ineluctable. El padre actúa como maestro, sacerdote y portador de la ley ante el público de los hijos. A través del dictamen "Y mañana, a la escuela", el padre instaura la temporalidad de la escuela, el Estado y la ley al interior del hogar. Desde la infancia, el individuo aparece como ya interpelado por la configuración ideológica familiar - paternal, maternal, conyugal, fraterna -: su identidad es única, implacable y patética.

El poema "España, aparta de mí este cáliz" - que le da título a la colección de textos que Vallejo escribió, inspirado en la Guerra Civil Española, publicados luego de su muerte en 1939 - tiene la entonación de un himno infantil, en algún sentido similar a las canciones e himnos infantiles que Bertold Brecht escribió entre 1930 y 1950, en que formula una utopía de infancia dirigida a los niños. ${ }^{6}$ "España, aparta de mí este cáliz" es una oda dirigida a las futuras generaciones de niños republicanos, como potenciales agentes de construcción de un nuevo orden social, de una nueva patria; sin embargo, paradójicamente, el poema contempla, desde el inicio, la posibilidad de la derrota, de que caiga España, que aparece como madre y maestra:

Niños del mundo,

si cae España-digo, es un decir-

si cae (VALLEJO, 1988: 481)

El sujeto poético pone en duda su propia capacidad enunciativa y desde el título - cita de los evangelios - enuncia la ambigüedad constitutiva de toda épica sacrificial, así como el lugar dilemático del escritor, desgarrado ante el deseo de intervenir e impotente ante la historia. El poema, que probablemente alude al lema de Karl Marx "¡Proletarios del mundo, uníos!", es un llamamiento al niño a través de la repetición rítmica, litúrgica, que enuncia la pérdida de la esperanza y la cercanía de una suerte de fin de los tiempos.

Si cae-digo, es un decir-si cae

España, de la tierra para abajo,

niños, ¡ cómo vais a cesar de crecer!

¡cómo va a castigar el año al mes!

¡Cómo van a quedar en diez los dientes,

en palote el diptongo, la medalla en llanto! (...)

¡Cómo vas a bajar las gradas del alfabeto

hasta la letra en que nació la pena! (VALLEJO, 1988: 481) 


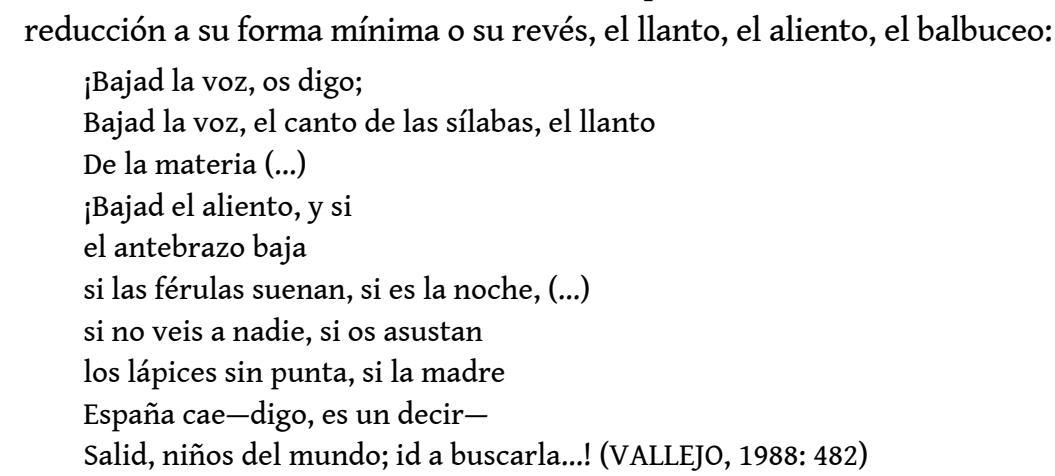
reducción a su forma mínima o su revés, el llanto, el aliento, el balbuceo:

¡Bajad la voz, os digo;

Bajad la voz, el canto de las sílabas, el llanto

De la materia (...)

¡Bajad el aliento, y si

el antebrazo baja

si las férulas suenan, si es la noche, (...)

si no veis a nadie, si os asustan

los lápices sin punta, si la madre

España cae-digo, es un decir-

Salid, niños del mundo; id a buscarla...! (VALLEJO, 1988: 482) desde una cierta autoridad, también supone la cancelación de la nominación, su

Si bien se posiciona desde el lugar de enunciación del autor/adulto, el yo poético no es una voz didáctica, portadora de saber: su pedido "bajad la voz" escenifica la impotencia del lenguaje poético ante la caída de España, cuya pérdida deja a los niños desamparados, sin lenguaje y sin sentido histórico. ${ }^{7}$ La infancia, escenificación de la negatividad del lenguaje poético, signo de la fragmentación de la experiencia histórica y cuestionamiento de la conciencia del sujeto hablante, por su carácter densamente experimental, contradice la lectura que la crítica ha hecho del poemario escrito en honor a la Guerra Civil Española como recuperación de la gramaticalidad y reposición de los valores del nombrar (ORTEGA, 1988: 611). Carentes de protección, solos ante el peligro, amenazados por la caída de la madre-España, los niños deberán, por sí mismos, "ir a buscarla". Este niño que, recién llegado al mundo, atestigua la caída de la patria, señala no sólo la crisis del lenguaje sino de la propia colectividad socio-política.

Vallejo escribió el cuento infantil Paco Yunque en Madrid en 1931, en respuesta al pedido de un cuento infantil por parte de un editor español, quien más tarde lo rechazaría por ser demasiado triste, según afirma la viuda Georgette Vallejo, quien se encargaría de publicarlo en forma póstuma (VALLEJO, 1998: 25). En sus apuntes biográficos, Georgette Vallejo ubica a Paco Yunque como parte del conjunto de textos escritos luego del segundo viaje del escritor a la unión soviética, sobre los cuales afirma: “Todas estas obras están suscitadas por la solidaridad de Vallejo con la humanidad explotada y avasallada (...). En Vallejo, especialmente despojado de apetitos individuales y de conceptos interesados, el revolucionario marxista nos lega: (...) hasta un cuento para niños." (DE VALLEJO, 1977: 133) Si bien Paco Yunque posee un propósito didáctico explícito en su temática y su estructura formal, resulta fundamental tomar distancia de dicha lectura en clave marxista y explorar el modo específico en que el texto investiga la sensibilidad del niño marginado. En el Perú de la época existía la institución andina del criadazgo, relación de dependencia en los hogares privados que implicó la sumisión de niños ilegítimos, indígenas, pobres o huérfanos, dedicados al trabajo doméstico informal, considerados 
sujetos carentes de derechos (MILANICH, 2005: 35). ${ }^{8}$ Paco Yunque escenifica el desvalimiento del niño pobre en ese orden, que abarca tanto la vida doméstica como el espacio escolar.

31 Paco Yunque es un niño campesino pobre, hijo de un peón de estancia y una criada, que sufre las vejaciones de Humberto Grieve, su compañero de clase, hijo del inglés gerente de la compañía de ferrocarriles y alcalde del pueblo. El cuento sucede en la escuela de la sierra, espacio marcado por relaciones de disciplina, obediencia, por un régimen jerárquico corporal e intelectual de premios y castigos. Paco ingresa al orden escolar como sujeto carente de derechos: perdida la de por sí precaria protección del ambiente rural familiar - dado que su padre es el peón y su madre la criada del padre de Humberto Grieve -, Paco se encuentra subordinado al hijo del amo y a la disciplina escolar: "a Paco le habían hecho venir del campo para que acompañe a Humberto y para que juegue con él" (VALLEJO, 1998: 384). Paco es criado del niño Humberto, sometido a sus deseos y carente de derechos. El texto enuncia el extrañamiento del niño ante la escuela:

En el campo hablaba primero uno, después otro y después otro. A veces, oyó hablar hasta a cuatro o cinco personas juntas. Era su padre, su madre, don José, el cojo Anselmo y la Tomasa. Con las gallinas eran más. Y más todavía con la acequia, cuando crecía... Pero no. Eso no era voz de personas sino otro ruido, muy diferente. Y ahora sí que esto del colegio era una bulla fuerte, de muchos. Paco estaba asordado. (VALLEJO, 1998: 382)

Fuera de su mundo oral, rural, comunitario, al entrar a la escuela el niño se somete a una sociabilidad institucional, masiva, violenta. La escuela es "el prototipo de la alienación social" ha señalado Adorno (ADORNO, 1998: 186). Como escenario institucional de la vida civil, la escuela secuestra al niño, le expropia su lenguaje y su sensibilidad regional y lo inviste con la lógica de la alienación moderna. La narración se vuelve jadeante, se fragmenta para dar cuenta, al nivel de la forma, del shock en la percepción infantil:

Paco, sin soltar su libro, su cuaderno y su lápiz, se había quedado parado en el medio del salón, entre las primeras carpetas de los alumnos y el pupitre del profesor. Un remolino se le hacía la cabeza. Niños. Paredes amarillas. Grupos de niños. Vocerío. Silencio. Una trancada de sillas. El profesor. Ahí, solo, parado, en el colegio. Quería llorar (VALLEJO, 1998: 382)

Sería posible trazar una relación entre la experiencia de Vallejo como tutor del hijo de un terrateniente en la Sierra de Pasco, Perú, su trabajo como maestro, en Santiago de Chuco, en Trujillo y en Lima, el escenario escolar del texto y la serie de debates de la época en torno de la institución pedagógica. Como se mencionó, Mariátegui consideraba a la escuela laica y obligatoria como aplanadora de la diferencia individual, atravesada por desigualdades de clase y de raza y por la sumisión económica y social.

Ahora bien, si el texto ha sido leído como un ejercicio formulaico de realismo socialista próximo al realismo crítico de Máximo Gorki ${ }^{9}$-, cabría repensar críticamente el modo en que emerge allí la crítica social. Rechazado como "demasiado triste", Paco Yunque presenta un mundo expresivamente denso, emocionalmente cargado, en que los personajes aparecen como marionetas del orden y las jerarquías sociales. Un ejemplo claro es el personaje bestial, abusivo y codificador de Humberto Grieve que repite la frase "Paco Yunque es mi muchacho". Grieve es una caricatura del niño hijo de gringo, hijo de extranjero que miente y se vanagloria de su poder monetario y social, lo que provoca la burla de todos los niños..$^{10}$ Otro ejemplo es el profesor, que recompensa las transgresiones de Humberto Grieve en lugar de castigarlo: 
¿Quién era el profesor? ¿Por qué era tan serio y daba miedo? Yunque seguía mirándolo. (...) se parecía a otros señores que venían a la casa y hablaban con el patrón. Tenía un pescuezo colorado y su nariz parecía moco de pavo. Sus zapatos hacían risss -risss, -rissssss, cuando caminaba mucho. (VALLEJO, 1998: 395)

El profesor es de un histrionismo histérico, descripto en forma caricaturesca, como un burócrata-payaso. Mezcla el terror con el ridículo, es parte del "sumiso séquito de capituleros", como llama Mariátegui a los maestros (MARIÁTEGUI, 2005: p. 108). La escuela de Paco Yunque, escenario de castigos y sometimiento del cuerpo del niño, está ordenada temporal y espacialmente de forma jerárquica piramidal: el maestro ocupa el vértice y en la base se ubican los niños de acuerdo a su rango y posición social.

Debido a la mezcla exasperada de la caricatura cómica con lo terrorífico de la sumisión social y la marginación del niño, Paco Yunque dificulta una lectura del texto como realista socialista, incluso dado su evidente cometido de crítica social. En lugar de una identificación didáctica con los personajes, el texto genera la distancia crítica que Brecht ha analizado en su teoría del distanciamiento en el teatro épico (BRECHT, 1964). Sumergiendo al lector en la sensibilidad del niño marginado, su experiencia de alienación y extrañamiento social y escolar, el texto escenifica una doble búsqueda: por un lado, del niño como núcleo de crítica social y reflexión sobre el sistema educativo y, por otro, de una estética que en su exasperación y crítica de los códigos, de cuenta de la perspectiva caótica de ese niño.

\section{Conclusión}

Dada su alteridad, la sensibilidad del niño campesino, criado, indígena, emerge en los textos de Vallejo ligada a una serie de rupturas de las convenciones culturales y discursivas. Se trata de un lenguaje que explora la sensorialidad visual, auditiva, táctil y gustativa, así como el momento de ingreso en el orden simbólico, en que deviene sujeto para las instituciones del Estado. A través de este tipo de estrategias formales, Vallejo consigue atrapar trazos, indicios, registros de las sensaciones, afectos y percepciones del niño marginal, de difícil acceso para la historia cultural. Esto se verifica tanto en sus textos poéticos como prosísticos, para adultos y niños: allí, la sensibilidad infantil apunta a lo sombrío, vulnerable y desprotegido, aquello ignorado $\mathrm{u}$ olvidado por el mundo adulto, por su efecto perturbador, y trastoca las jerarquías de la representación y de lo representado. La infancia apunta a la posibilidad de constitución de un orden social futuro, pero también a su caída, la crisis de los discursos y de la comunidad social. La sensibilidad infantil, inmersa en una experiencia de alienación y extrañamiento, es capaz de iluminar, e incluso subvertir, las jerarquías de los discursos sociales y los modos de representación. 


\section{BIBLIOGRAFÍA}

ADORNO, Theodor W, Critical Models. Interventions and Catchwords, New York, Columbia University Press, 1998.

ALTHUSSER, Louis, "Ideology and Ideological State Apparatuses (Notes towards an investigation)", en Lenin and Philosophy and Other Essays, New York, MRPress, 1971.

BLOCH, Ernst et al., Aesthetics and Politics, New York, Verso, 2002.

BOSI, Alfredo, "La parábola de las vanguardias latinoamericanas", en Jorge Schwarz, Las vanguardias latinoamericanas. Textos programáticos y textos críticos, México, FCE, 2002.

BRECHT, Bertold, Brecht on Theatre: The Development of an Aesthetic. New York, Hill and Wang, 1964.

CLAYTON, Michelle, Poetry in Pieces. César Vallejo and Lyric Modernity, Berkley, Univ. Of California Press, 2011.

DE VALLEJO, Georgette, “Apuntes biográficos”, César Vallejo, Obras Completas, Barcelona, Editorial Laia, 1977.

FOSTER, Hal, Compulsive Beauty, Cambridge, Mass, MIT Press, 1993.

FRANCIOLLI, Marco, (ed.) Les Enfants Terribles. The Language of Childhood in Art. Milano, Silvana Editoriale, 2004.

FRANCO, Jean, "La Temática: de Los Heraldos Negros a los "Poemas Póstumos" Obra Poética Completa , Madrid, Ed. Archivos, 1988.

FRANCO, Jean, César Vallejo. The Dialectics of Poetry and Silence, New York, Cambridge Univ. Press, 1976.

GUY, Donna, "The Pan American Child Congresses, 1916 to 1942: Pan Americanism, Child Reform and the Welfare State in Latin America", Journal of Family History, 23, 1998, Pp. 272-291.

GUY, Donna,"The State, the Family and Marginal Children in Latin America”, en Tobias Hecht (ed.) Minor Omissions: Children in Latin American History and Society, Wisconsin, Univ. of Wisconsin, 2002.

GUY, Donna, Women Build the Welfare State, Duke Univ. Press, Durham, 2009.

KRAUSS, Rosalind, The Originality of Avant-garde and Other Modernist Myths, Cambridge, MIT Press, 1988.

KRISTEVA, Julia, “El tema en cuestión: el lenguaje poético", C. Lévi Strauss, Seminario: La Identidad , Barcelona, Petrel, 1981.

LAVRIN, Asunción, "La niñez en México e Hispanoamérica: rutas de exploración” en Aizpuru y Rabell (comps.), La familia en el mundo Iberoamericano, México: UNAM, 1994.

LEINAWEAVER, Jessaca B, The circulation of children. Kinship, Adoption and Morality in Andean Peru, Durham, Duke Univ., 2008.

LÓPEZ VIGIL, Ricardo, “Prólogo” Vallejo, César, Novelas y cuentos completos. Lima, Ediciones Copé, 1998. 
MARIÁTEGUI, José Carlos, “El proceso de la instrucción pública”, Siete ensayos de interpretación de la realidad peruana, Buenos Aires, El Andariego, 2005.

MARIÁTEGUI, José Carlos, “Temas de educación”, Obras completas., Perú, Ed. Amauta, 1970.

MAZZARI, Marcus Vinicius, Labirintos de aprendizagem. Pacto fáustico, romance de formação e outros temas de literatura comparada, São Paulo, Editora 34, 2010.

MILANICH, Nara, Children of Fate. Childhood, Class and the State in Chile. Durham, Duke Univ. Press, 2005.

MOLLOY, Sylvia, Acto de presencia. La escritura autobiográfica en Hispanoamérica, México, El Colegio de México / Fondo de Cultura Económica, 1996.

ORTEGA, Julio, "La Hermenéutica vallejiana y el hablar materno", Obra Poética Completa, Madrid, Ed. Archivos. 1988.

PILOTTI, Francisco y RIZZINI, Irene, (eds.) A arte de governar crianças. A história das políticas sociais, da legislação e da assistência da infância no Brasil, Rio de Janeiro, Instituto Interamericano Del Niño / AMAIS.

ROSENBERG, Fernando, The Avant-garde and Geopolitics in Latin America. Pittsburgh, Pittsburgh University Press, 2006.

ROAZEN, Daniel Heller, Echolalias- On the Forgetting of Language, New York, Zone Books, 2005.

UNRUH, Vicky, Latin American Vanguards. The Art of Contentious Encounters, Berkeley, University of California Press, 1994.

VALLEJO, César, Correspondencia completa, Ed. Jesús Cabel, Lima, Pontificia Universidad Católica del Perú, 2002.

VALLEJO, César, “Autopsia del superrealismo”, en Jorge Schwarz, Las vanguardias latinoamericanas. Textos programáticos y textos críticos, México, FCE, 2002, Pp. 465-470

VALLEJO, César, Obra Poética, Madrid, Ed. Archivos, 1988.

VALLEJO, César, Novelas y cuentos completos, Lima, Ediciones Copé, 1998.

\section{NOTAS FINALES}

1. La "escena", como apuntó Jacques Rancière, es la inscripción del evento estético en una constelación variable de modos de percepción, afectos y modos de interpretación, y constituye la comunidad sensible e intelectual que torna posible esas relaciones (RANCIÈRE, 2013: 11).

2. Es el caso del romanticismo brasileño, de Joaquim Nabuco y Gonçalves de Magalhâes, leído por Silviano Santiago (SANTIAGO, 2004: 20).

3. Fernando Rosenberg afirma que los artistas de vanguardia experimentan una suerte de "retorno populista" en la década de 1930 y 1940 (ROSENBERG, 2006: 150).

4. En "Anotaciones", afirma, sobre la politización del artista: "en el verdadero artista, las opiniones políticas importan poco", y en "Literatura proletaria": "en mi calidad de artista, no acepto ninguna consigna o propósito extraño, que aún respaldándose de la mejor buena intención, someta mi libertad estética al servicio de tal o cual propaganda política." (SCHWARZ, 2002: 517-518.

5. "La pareja familia-escuela ha reemplazado la pareja familia-Iglesia" (ALTHUSSER, 1971: 153-154). 
6. Entre los himnos infantiles de Bertold Brecht, pueden citarse: “Children's song” (1937), “To those born after" (1939), "Children's crusade" (1939), "Children's hymn" (1950) y "Little postwar song" (1950). Dice Marcus Vinicius Mazzari sobre ellos: "Brecht formula, em novo ciclo de canções infantis, uma espécie de utopia da infância, (...) dirigida, em seus ciclos de canções infantis, diretamente as crianças" (Mazzari, 2010: 222).

7. "Al final la pérdida de España dejará a los niños sin sombre y sin lenguaje porque el extravío del sentido histórico equivale a la regresión, al páramo sin habla," (ORTEGA, 1988: 608).

8. Nara Milanich afirma sobre la institución Latinoamericana del criadazgo, "Al no regular la ley la relación entre los amos y los criados, estos niños son vistos más como beneficiarios de la benevolencia que como portadores de sus propios derechos. Este hecho contribuye en gran medida a su status de sumisión en los hogares privados." (MILANICH, 2005: 33). Para un análisis del fenómeno de la circulación de los niños indígenas en la cultura Andina ver LEINAWEAVER, 2008).

9. Ricardo López Vigil lee a Paco como emblema del proletariado y a Fariña como símbolo leninista. (VIGIL, 1998: 7.) Por su lado, Georgette Vallejo analiza un garabato por el que Vallejo habría indicado a la editorial el modo y el lugar en que se debían incluir las ilustraciones en el libro infantil, resaltando su contenido de crítica social. (VALLEJO, 1998: 402.)

10. “No, señor- decía Humberto Grieve-. Porque en mi salón [los peces] no se mueren. Porque mi salón es muy elegante. Porque mi papá me dijo que trajera peces y que podía dejarlos sueltos entre las sillas. Paco Fariña se moría de risa. Los Zumiga también. El chico rubio y gordo, de chaqueta blanca y el otro, cara redonda y chaqueta verde, se reían ruidosamente. ¡Qué Grieve tan divertido! ¡Los peces en su salón! ¡Entre los muebles! ¡Como si fuesen pájaros! Era una gran mentira lo que contaba Grieve. (VALLEJO, 1998: 389)

\section{RESÚMENES}

El artículo examina la "escena" de infancia en una selección de textos del escritor peruano César Vallejo. Se abordan los sentidos por los cuales la sensibilidad del niño campesino, indígena, emerge en Vallejo a través de una ruptura de las convenciones culturales. Con ese fin, se establecen relaciones con el modo en que las vanguardias europeas y latinoamericanas concibieron a la infancia y con los debates de una serie de intelectuales alrededor de cuestiones sociales y modelos pedagógicos en América Latina. Se argumenta que en los textos de Vallejo la infancia combina un posicionamiento político alrededor de la infancia excluida o marginada y una serie de búsquedas formales ligadas a la sensibilidad del niño marginado, excluido de la visibilidad social.

L'article examine la « scène » de l'enfance, dans une sélection de textes de l'écrivain péruvien César Vallejo. Nous allons étudier la sensibilité de l'enfant autochtone, aborigène, élevé en milieu rural, laquelle se manifeste à partir d'une rupture des conventions culturelles. Des rapprochements sont faits avec la façon dont les avant-gardes européennes et latino-américaines ont pensé l'enfance et avec les débats menés par plusieurs intellectuels autour des questions sociales et des modèles pédagogiques en Amérique latine. Dans les textes de Vallejo, ce sujet s'associe à un positionnement politique à l'égard de l'enfance exclue ou marginalisée, et également à une série de recherches formelles liées à la sensibilité de l'enfant marginalisé, exclu de la visibilité sociale. 
ÍNDICE

Mots-clés: enfance, sensibilité, César Vallejo, avant-gardes.

Palabras claves: infancia, sensibilidad, César Vallejo, vanguardia.

\section{AUTOR}

ALEJANDRA JOSIOWICZ

CPDOC-FGV (Pós-doutorando) e IIEGE-CONICET (Pesquisador)- alejandra.josiowicz@gmail.com 